\title{
Minimally Invasive Adrenalectomy: Technical Aspects of the Laparoscopic and the Robotic Approach
}

\author{
Silviu Tiberiu Makkai-Popa, Beniamino Pascotto, Luca Arru, Vito De Blasi, Martine Goergen, Juan Santiago Azagra \\ Department of General Surgery, Centre Hospitalier de Luxembourg, Luxembourg
}

Corresponding author: Juan Santiago Azagra, MD

Department of General Surgery

Centre Hospitalier de Luxembourg

4, rue Ernest Barble L-1210

Luxembourg

Telephone: +35244112085

Fax: +35244116274

E-mail: Azagra.JS@chl.lu

\section{Rezumat}

Abordul mini-invaziv în supra-renalectomii: aspecte tehnice în abordul laparoscopic și robotic

Suprarenalectomia este în zilele noastre o intervenție chirurgicală eminamente realizată prin procedee minim-invazive. Scopul acestui articol este să descrie detaliile tehnice ale suprarenalectomiei laparoscopice şi robotice prin prezentarea a 4 cazuri şi discuția avantajelor şi dezavantajelor fiecarei tehnici.

Cuvintele cheie: suprarenalectomie, chirurgie laparoscopică, chirurgie robotică

\section{Abstract}

Adrenalectomy is nowadays a procedure routinely performed by minimally invasive surgery. In this article we aim to describe in depth our technique for laparoscopic and robotic left and right adrenalectomies, by using four cases and discussing the advantages and disadvantages of each technique.

Key words: adrenalectomy, laparoscopic surgery, robotic surgery

\section{Introduction}

We live in an era when surgery has taken a turn towards minimally invasive techniques. Laparoscopy, and lately, robotic 
surgery is gaining ground as being as safe and effective as laparotomy in the treatment of most of the tumours handled by the general surgeon and despite some minor debates in this area of minimally invasive oncologic surgery, laparoscopy and moreover robotic surgery have become indispensable to the general surgeon's armamentarium (1-5).

Adrenalectomy was first described as a technique in 1926 by Roux and Mayo, only to be regarded as difficult and extremely morbid in 1942 by Fey (6-8). Once the technique and usefulness of open adrenalectomies were recognized, with the development of laparoscopy came the first laparoscopic adrenalectomy performed by Gagner in 1992 (9). Nowadays laparoscopic adrenalectomy is the approved approach to adrenalectomy in most cases requiring such a procedure (10). There are two main approaches - transperitoneal and retroperitoneal and both of them are significantly less difficult to withstand and less prone to complications, when compared to the open approaches that require either a large median laparotomy, a bi-subcostal incision or even a thoraco-phreno-laparotomy (11). Besides, they seem to require less operative time and obviously as with any laparoscopic surgery shorter hospital stay and shorter recovery times (11). The advantages of the robot have been widely discussed and praised throughout literature and all of them apply to adrenalectomies as well $(12,13)$.

Thus, the purpose of our paper is to present our operative technique, both laparoscopic and robotic by presenting 4 cases - one laparoscopic and one robotic for each side, left and right.

\section{Right Lateral Transabdominal Laparoscopic Adrenalectomy}

The first case is a 53 years-old female patient with a body mass index (BMI) of $25,1 \mathrm{~kg} / \mathrm{m}^{2}$ presenting a secreting adrenal adenoma. The patient's main complaints were difficult to control hypertension, diabetes mellitus and dyslipidaemia. The CT-scan showed an adrenal mass of $18 \mathrm{~mm}$ and an iodocholesterol scintigraphy confirmed a secreting adrenal adenoma which was an indication for surgery. The patient was positioned in a complete left lateral position on a bean bag with the right arm in abduction at 90 degrees on a padded support making sure the position is comfortable for the patient so as to avoid brachial plexus elongation (Fig. 1). In order to open up the angle between the ribs and the iliac crest we position the patient in such a way as to allow breaking the table in order to achieve this goal.

When performing laparoscopic procedures in our unit the standard is to use a $0^{\circ}$ scope and we place the trocars in order to achieve a direct, frontal view of the structure we are working on. The epigastric trocar is thus used for the liver retractor and the three other ports are used as a working triangulation unit with the camera in the centre.

The first step in the dissection is performing a Kocher manoeuvre in order to expose the inferior vena cava. To obtain better visibility of the adrenal gland the right triangular ligament of the liver is partially mobilized. All throughout the dissection we try to touch the gland as little as possible. We proceed to a control of the adrenal vein on the right posterolateral aspect of the inferior vena cava. We usually control this vein by means of a vessel sealing device but if need be it can also be controlled with either a Hem-O-Lok or a standard metal clip. Dissection then aims to

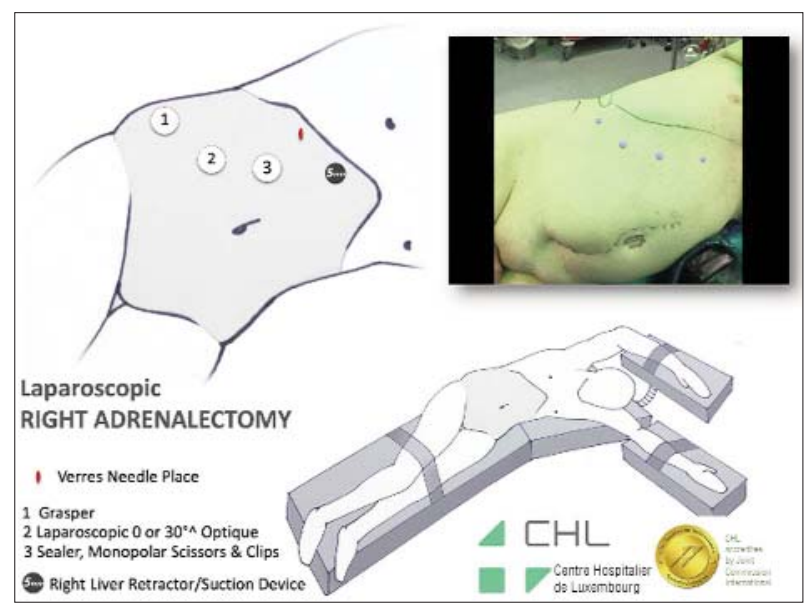

Figure 1. Patient and trocar positioning for a right lateral transabdominal laparoscopic adrenalectomy 
control the 3 possible arterial sources of arterial supply: superior suprarenal artery branching from the inferior phrenic artery, middle suprarenal artery branching from the abdominal aorta and inferior suprarenal artery branching from the renal artery

Because of the variability of the arterial blood supply we usually perform this step of the dissection using a vessel sealing device so as to avoid bleeding which could potentially be extremely difficult to handle due to special restriction of the operative site. Once all the medial and inferior connections of the adrenal gland have been transsected, we proceed to dissecting the posterior and cranial pole until the psoas and the diaphragm. Once freed, the specimen is placed in a plastic retrieval bag and extracted. Fig. 2 shows the steps of the procedure.

For this particular case the duration of the procedure was 80 minutes and the patient went back home on the $2^{\text {nd }}$ postoperative day. No postoperative complications were recorded.
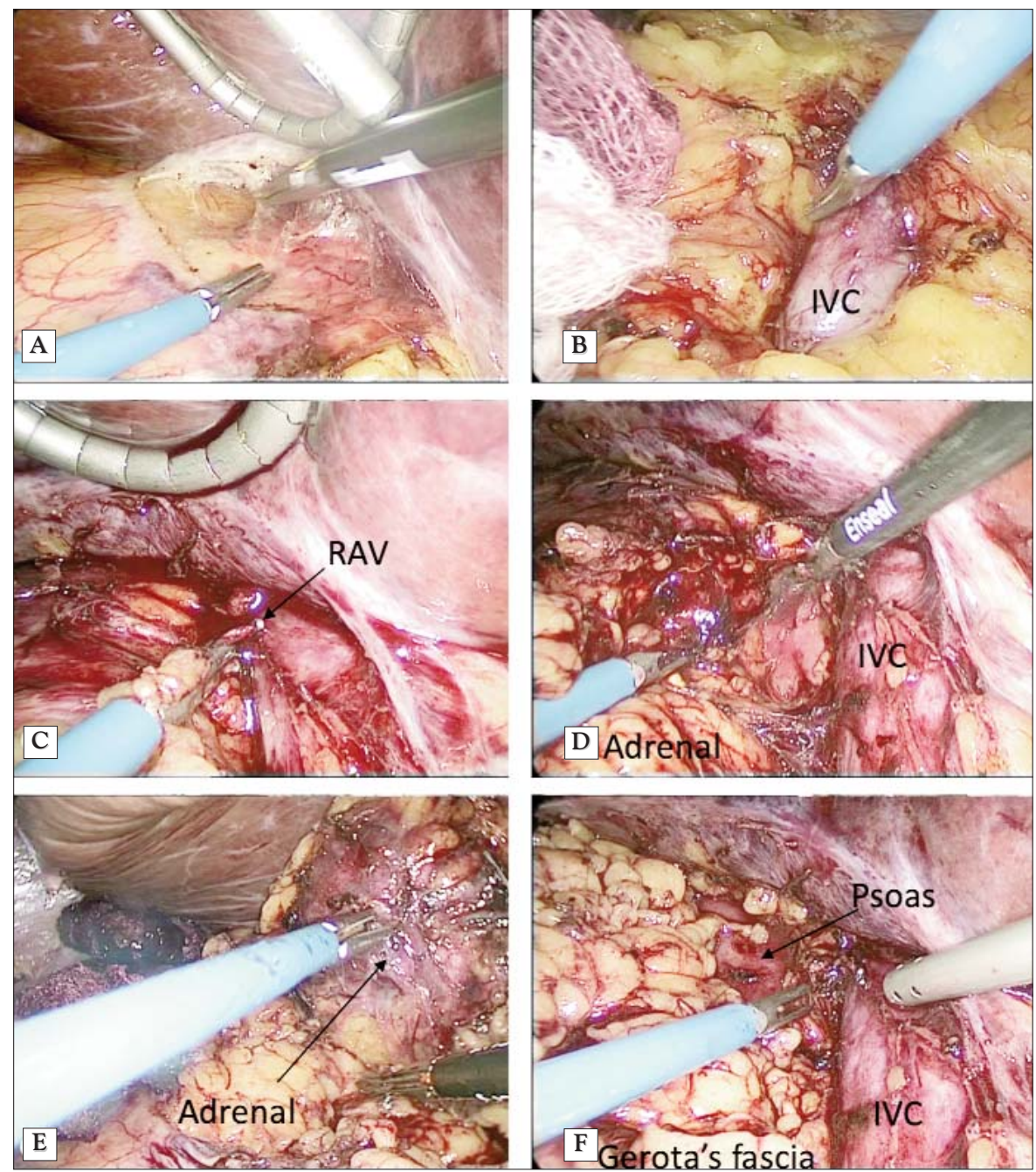

Figure 2. Steps of a right lateral transabdominal laparoscopic adrenalectomy: (A) - mobilisation of the right colonic flexure and Kocher manoeuvre; (B) - exposure of the right side of the inferior vena cava; (C) - clipping of the right adrenal vein; (D) - progressive dissection of the medial border of the right adrenal gland; (E) - inferior, lateral and posterior dissection of the right adrenal gland; $(F)$ - view of the resection bed (IVC - inferior vena cava, RAV - right adrenal vein). 


\section{Right Lateral Transabdominal Robotic Adrenalectomy}

The second case is that of a 54 years-old male patient with a BMI of $31,2 \mathrm{~kg} / \mathrm{m}^{2}$ that was diagnosed with a right pheochromocytoma. The suspicion of a pheochromocytoma in this case was quite difficult to confirm preoperatively, but was suspected based on the biological markers of cathecolamine hypersecretion. The clinical picture was not typical of a pheochromocytoma and the MIBG scintigraphy was negative.

As you can see, when migrating from the laparoscopic to the robotic approach the patient positioning remains similar in our unit (Fig. 3). The patient cart is positioned behind the patient and the arms of the robot are placed on a line parallel to the right costal margin. Arm number 4 is placed in the epigastric region and arm number 1 above the anterior superior iliac crest leaving enough space so as not to have conflicts. The remaining 2 arms are placed on a line between the first two, equally spread apart. An assisting trocar can be placed in the epigastric region or periumbilical region for the liver retractor. The camera is placed on the number 2 port, a scissor or a vessel sealer on the number 3 port and the fenestrated bipolar and the Cadiere forceps are used on the number 1 and 4 ports and are interchanged depending on the needs encountered during

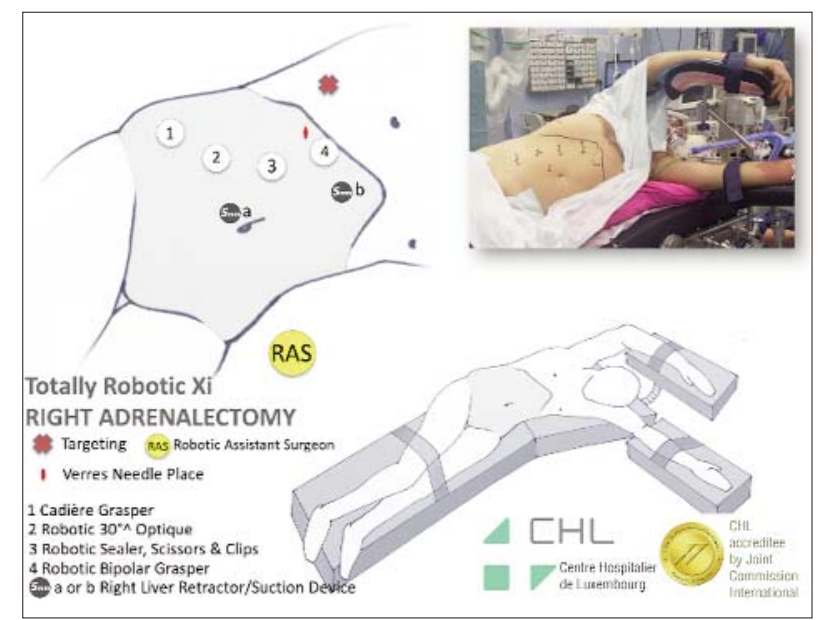

Figure 3. Patient and trocar positioning for a right lateral transabdominal robotic adrenalectomy. dissection. The steps of the dissection follow the same principles as previously described for the laparoscopic right adrenalectomy - control of the vein followed by progressive dissection of all possible arterial supply to the gland. Because of the clinical suspicion of pheochromocytoma, which was later confirmed on pathology, the tumour was not touched before obtaining outflow control. The duration of the surgery was 115 minutes with 10 minutes of docking and adhesiolysis and 95 minutes of console time. Again, the patient was discharged on postoperative day 1 , without complications and pathology confirmed a pheochromocytoma.

\section{Left Lateral Transabdominal Laparoscopic Adrenalectomy}

For a left laparoscopic adrenalectomy, we would like to present you the case of a 63 years-old female with a BMI of $23 \mathrm{~kg} / \mathrm{m}^{2}$ presenting with a $29 \mathrm{~mm}$ left adrenal mass which based on the clinical and biological characteristics was considered compatible with a pheochromocytoma. Figure 5 shows the positioning of the patient on the operating table as well as the port positioning in such a case. In a left laparoscopic adrenalectomy we prefer to use a 3 trocar technique in which a first $10 \mathrm{~mm}$ port is introduced in the left flanc, on the left mid-clavicular line and then under direct vision two other ports are placed - a $5 \mathrm{~mm}$ port in the epigastric region, closer to the midline compared to the first and a second 10 $\mathrm{mm}$ port located $2-3 \mathrm{~cm}$ above the iliac crest so as not to limit the movement range.

The first stage of the dissection consists in liberating the splenocolic ligament as well as the parietal attachments of the spleen and the splenorenal ligaments. By using a complete right lateral position, the mobilisation of the spleen is made easier by the force of gravity. Once the spleno-phrenic ligament is transected and the plane between the Gerota's fascia and the pancreas is entered the left inferior phrenic vein is used as a guide to the left adrenal vein which is dissected and transected between two clips. Once the vein is transsected 


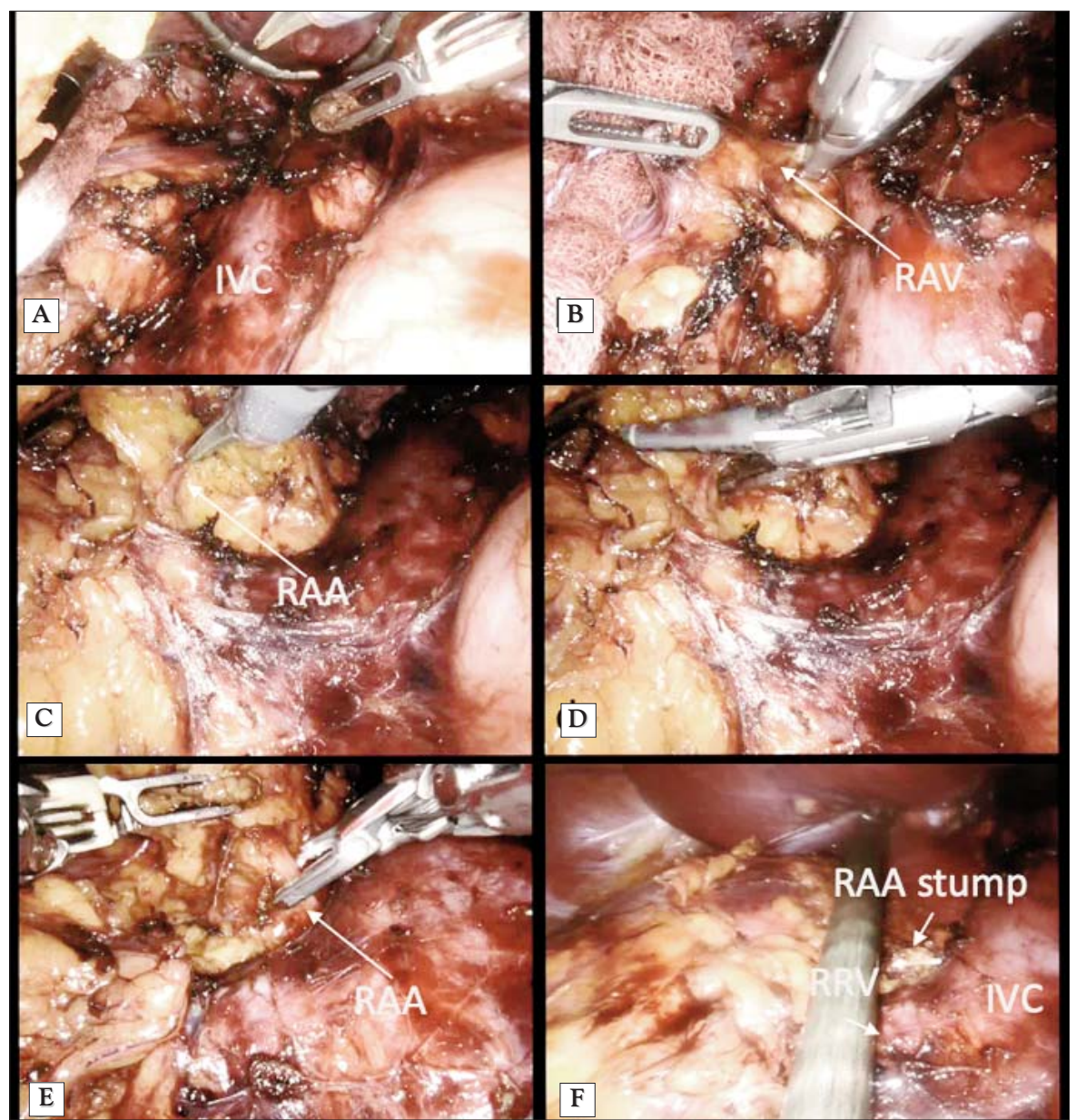

Figure 4. Steps of a right lateral transabdominal robotic adrenalectomy: (A) - mobilisation of the right colonic flexure and Kocher manoeuvre exposing the right side of the inferior vena cava; (B) - exposure of the right adrenal vein which is dissected and transsected using a vessel sealer; (C) - a right adrenal artery is dissected;

(D) - small calibre arteries are transsected with a vessel sealer; (E) - larger calibre arteries require clipping; (F) - view of the resection bed (IVC - inferior vena cava, RAA - right adrenal artery, RAV - right adrenal vein RRV- right renal vein).

the dissection is carried out from lateral to medial in order to enter a plane just above anterior to the psoas muscle and the diaphragm and by means of a vessel sealing device all the adhesions between the upper pole of the kidney and the adrenal gland are cut. Finally, the adrenal artery is clipped and transected and the resection specimen is freed completely. Once again, care should be taken because of the variability of the arterial blood supply also mentioned above. In this case, the

Figure 5. Patient and trocar positioning for a left lateral transabdominal laparoscopic adrenalectomy.

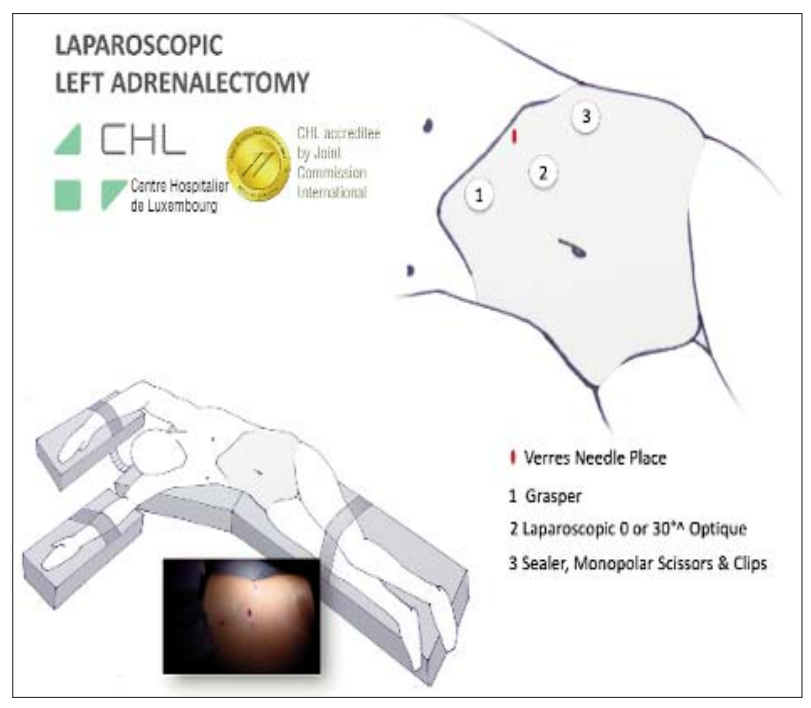






Figure 6. Steps of a left lateral transabdominal laparoscopic adrenalectomy: (A) - mobilisation of the left colonic flexure; (B) - exposure of the left inferior phrenic vessels;

(C) - dissection of the left adrenal vein (LAV), the left renal vein and the splenic veins are also visible; (D) - the vein is clipped and transsected; (E) - inferior, and lateral dissection of the left adrenal gland; $f$ - posterior dissection of the left adrenal gland in order to clear the resection bed (IPV - inferior phrenic vessels, LAV - left adrenal vein, LRV - left renal vein, LAA - left adrenal artery).

operative time was 52 minutes, the patient left the hospital on day 1 after the surgery and had no complications. The pathology of the tumour revealed a pheochromocytoma.

\section{Left Lateral Transabdominal Robotic Adrenalectomy}

The patient is a 45 years-old female, with a BMI of $22 \mathrm{~kg} / \mathrm{m} 2$, diagnosed with a Conn's adenoma incidentally during the workup of a difficult to treat hypertension. The patient had hyperaldosteronism with hypokalemia which raised the suspicion of a cortico-adrenal adenoma. It is in this context that an imaging workup was performed to rule out a suspicion of malignancy. The PET-scan, as well as the MIBG scintigraphy were in favour of an adenoma so we proceeded to performing a robotic left adrenalectomy. The size of the lesion on the CT scan was $2,5 \mathrm{~cm}$. The port placement can be seen in Fig. 7 . 


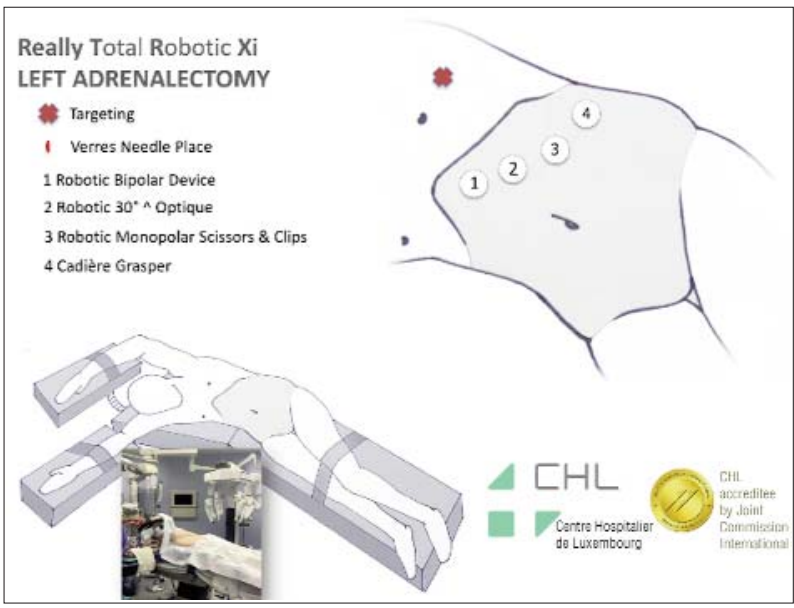

Figure 7. Patient and trocar positioning for a left lateral transabdominal robotic adrenalectomy.
The ports are placed in a line parallel to the border of the ribs, with the camera being placed in the second port. Ports 1 and 3 are used for grasping instruments whereas port number 4 is mainly used for the scissors. The dissection follows the same guiding thread as the laparoscopic approach which is the left inferior phrenic vein in order to identify the left adrenal vein without touching the tumour. The duration of the surgery was 61 minutes out of which the docking time represented 8 minutes. The patient left the hospital on the first day after surgery without any complication.

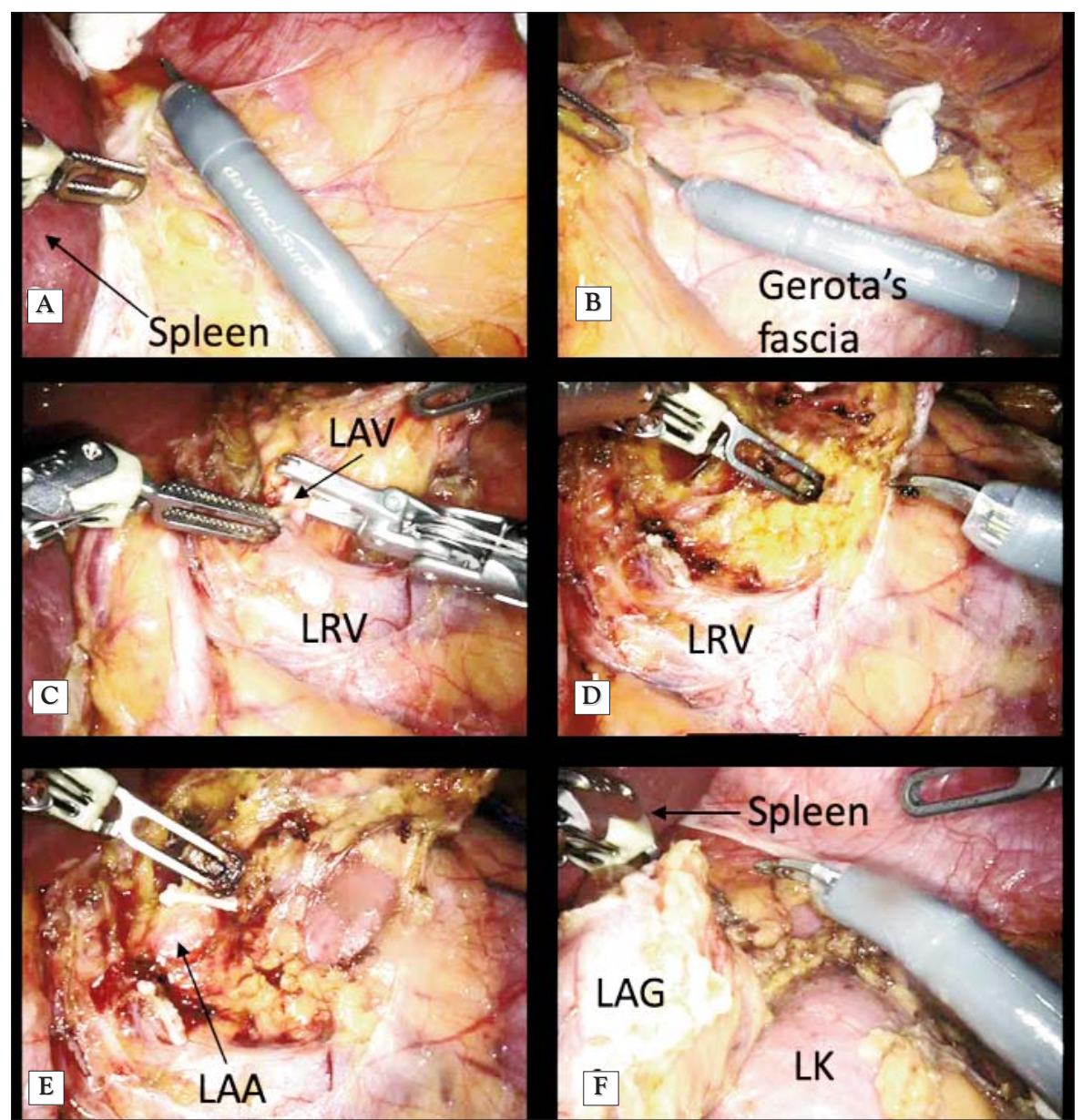

Figure 8. Steps of a left lateral transabdominal robotic adrenalectomy: (A) - mobilisation of the left colonic flexure; (B) - dissection of the spléno-renal ligament; (C) - dissection of the left adrenal vein; (D) - dissection of the inferior pole of the left adrenal gland;

(E) - control of a large arterial branch for the left adrenal gland; $(F)$ - completion of the lateral dissection (LAV - left adrenal vein, LRV - left renal vein, LAA - left adrenal artery, LAG - left adrenal gland, LK - left kidney). 


\section{Discussion}

Our service is a service traditionally oriented towards minimally invasive surgery for reasons which are related to the patient's well-being, as well as for economic and teaching reasons (14-16). Basically, the patients require a shorter hospital stay because the postoperative evolution is generally easier and thus reduces the costs related to the hospital stay. Another advantage of the minimally invasive surgical techniques we greatly value is the teaching potential of both the laparoscopic and the robotic approach.

However, when it comes to adrenalectomy there are some relative contra-indications to minimally invasive techniques which are the size of the tumour above $8 \mathrm{~cm}$, in our experience, and the suspicion of a malignant cortico-adrenal tumour, despite the fact that current literature debates more and more the feasibility of laparoscopic adrenalectomy for adrenocortical carcinomas $(17,18)$. The size limit of the tumour that can be safely handled by minimally invasive techniques has been largely debated throughout literature and it varies from $6 \mathrm{~cm}$ in some studies (19) to about $10 \mathrm{~cm}$ in other studies (20).

As far as the dissection goes, we prefer the use of an advanced vessel sealing device because of the faster sealing time and the reduced intraoperative blood loss (21) which allows us to safely control the arterial blood supply in most of the cases.

Between the two minimally invasive techniques, the laparoscopic method, as you can see from the cases above, requires in our setup fewer trocars compared to the robotic approach.

However, the limits of laparoscopy (lack of depth perception, poorer manoeuvrability, fulcrum effect, lack of coordination between the members of the team) are overcome when using a robot which allows for better depth perception, manoeuvrability leading to more intuitive gestures and allowing us to achieve "solo surgery".

\section{Conclusion}

Because of all of its advantages we prefer using a robotic approach in cases which are conflictive because either the size of the tumour or the patient's comorbidities, despite requiring an additional trocar and a longer time due to the docking. In our opinion, both laparoscopic and robotic adrenalectomy are highly standardized procedures that can be taught and carried on by surgeons with experience in minimally invasive surgery.

\section{Conflict of Interest}

The authors declare no conflicts of interests.

\section{References}

1. Angst E, Hiatt JR, Gloor B, Reber HA, Hines OJ. Laparoscopic surgery for cancer: a systematic review and a way forward. J Am Coll Surg. 2010;211:412-23.

2. Liu CA, Huang KH, Chen MH, Lo SS, Li AF, Wu CW et al. Comparison of the surgical outcomes of minimally invasive and open surgery for octogenarian and older compared to younger gastric cancer patients: a retrospective cohort study. BMC Surg. 2017;17:68.

3. Min SH, Won Y, Kim G, Lee Y, Park YS, Ahn SH et al. 15-year experience of laparoscopic gastrectomy in advanced gastric cancer: analysis on short-term and long-term oncologic outcome. Surg Endosc. 2019 (Online ahead of print).

4. Son GM, Kye BH, Kim MK, Kim JG. Reconsideration of the Safety of Laparoscopic Rectal Surgery for Cancer. Ann Coloproctol. 2019;35:229-37.

5. Wang S, Shi N, You L, Dai M, Zhao Y. Minimally invasive surgical approach versus open procedure for pancreaticoduodenectomy: A systematic review and meta-analysis. Medicine (Baltimore). 2017; 96:e8619.

6. Fey B. Traite de techniques chirurgicales. Place: Masson et Cie; 1942.

7. Mayo $\mathrm{CH}$. Paroxysmal hypertension with tumor of retroperitoneal nerve: report of case. Journal of the American Medical Assosciation. 1927;89:1047-50.

8. Welbourn RB. Early surgical history of phaeochromocytoma. Br J Surg. 1987;74:594-6.

9. Gagner M, Lacroix A, Bolte E. Laparoscopic adrenalectomy in Cushing's syndrome and pheochromocytoma. N Engl J Med. 1992; 327:1033.

10. Raffaelli M, De Crea C, Bellantone R. Laparoscopic adrenalectomy. Gland Surg. 2019;8:S41-S52.

11. Chai YJ, Kwon H, Yu HW, Kim SJ, Choi JY, Lee KE et al. Systematic Review of Surgical Approaches for Adrenal Tumors: Lateral Transperitoneal versus Posterior Retroperitoneal and Laparoscopic versus Robotic Adrenalectomy. Int J Endocrinol. 2014;2014: 918346.

12. Ahmed J, Cao H, Panteleimonitis S, Khan J, Parvaiz A. Robotic vs laparoscopic rectal surgery in high-risk patients. Colorectal Dis. 2017;19:1092-99. 
13. Kim WW, Lee YM, Chung KW, Hong SJ, Sung TY. Comparison of Robotic Posterior Retroperitoneal Adrenalectomy over Laparoscopic Posterior Retroperitoneal Adrenalectomy: A Single Tertiary Center Experience. Int J Endocrinol. 2019 eCollection 2019.

14. Braga M, Frasson M, Vignali A, Zuliani W, Civelli V, Di Carlo V. Laparoscopic vs. open colectomy in cancer patients: long-term complications, quality of life, and survival. Dis Colon Rectum. 2005;48:2217-23.

15. de'Angelis N, Gavriilidis P, Martinez-Perez A, Genova P, Notarnicola $M$, Reitano $E$ et al. Educational value of surgical videos on YouTube: quality assessment of laparoscopic appendectomy videos by senior surgeons vs. novice trainees. World J Emerg Surg. 2019;14:22.

16. Klaiber C, Metzger A, Z'Graggen K, Leepin H. From diagnostic laparoscopy to laparoscopic surgery). Helv Chir Acta. 1991;57:
693-7.

17. Kiernan CM, Lee JE. Minimally Invasive Surgery for Primary and Metastatic Adrenal Malignancy. Surg Oncol Clin N Am. 2019; 28:309-26.

18. Mirallie E, Blanchard C, Caillard C, Rodien P, Briet C, Mucci S et al. Adrenocortical carcinoma: Impact of surgical treatment. Ann Endocrinol (Paris). 2019;80:308-13.

19. Henry JF. Minimally invasive adrenal surgery. Best Pract Res Clin Endocrinol Metab. 2001;15:149-60.

20. Machado NO, Al Qadhi H, Al Wahaibi K, Rizvi SG. Laparoscopic Adrenalectomy for Large Adrenocortical Carcinoma. JSLS. 2015;19.

21. Patrone R, Gambardella C, Romano RM, Gugliemo C, Offi C, Andretta $C$ et al. The impact of the ultrasonic, bipolar and integrated energy devices in the adrenal gland surgery: literature review and our experience. BMC Surg. 2019;18:123. 